\title{
Direito Autoral e Contrato de Representação
}

\author{
- Oliveira e Silva \\ (Juiz de Direito da $4 .^{\text {a }}$ Vara Civel)
}

1. Sòmente agora a matéria de direito autoral vai sendo debatida, com maior intensidade, no âmbito do Poder Judiciário, mercê do desenvolvimento auspicioso, entre nós, do grande e do pequeno direito.

O teatro, o cinema, o rádio e a televisão adaptando romances, por um lado, e o crescimento de originais brasileiros, de comédia, revista ou drama, já passibilita controvérsias ou conflitos entre a inteligência criadora e o capital.

Recentemente, pronunciou-se a $1 .^{\text {a }}$ Câmara Civel do Tribunal de Justiça do Distrito Federal, em Acórdão de 3 de novembro de 1954, numa hipótese interessantíssima, talvez a primeira a ser ventilada, no país, sôbre representação dramática e direito de autor, numa contenda entre o brilhante teatrólogo sr. R. Magalhães Júnior e o ator sr. Raul Roulien.

Várias teses, de alta relevância, aí são discutidas e decididas, demonstrando o relator des. João Coelho Branco profundeza e agudeza no conhecimento do direito do autor em face do empresário que the contrata a representação da peça teatral. Daí o seu voto luminoso que servirá de roteiro na jurisprudência que se vai formando, a respeito, no Brasil.

Em primeiro lugar, discute o Acórdão de 3 de novembro de 1954 se a representacão da obra teatral, nos têrmos das leis em vigor, está ou não, sukordinada à existência de contrato entre as partes interessadas e cnde se expressem os direitos dominicais do autor. Ainda se, havendo autorização preliminar, precisa esta aperfeiçoar-se, concluir-se em convenção definitiva para que haja um contrato orgânico.

Discute, ainda, aquele Acórdão um ponto que se nos afigura fundamental na representação dramática ou na cessão de direitos: se o silêncio sôbre o que deve cáber ao autor importará em gratuidade, ou se, pelo contrário, é especìficamente oneroso tal contrato.

Finalmente, aborda, com mestria, perante a lei civil, a matéria da doação. Esta presumir-se-á ou deverá ser obrigatòriamente expressa?

2. Analisemos as teses constantes do mencionado Acórdão de 3 de novembro de 1954. Eis a primeira: a representação da obra teatral dependerá de contrato, entre as partes, onde fiquem assegurados o valor e extensão dos direitos autorais? 
Sem dúvida alguma. A condição do autor é, em regra, a da sua pobreza diante do entpresário detentor do capital. Assim, entre ambos, há um legítimo contrato de trabalho, sob a vigilância do Estado, com as características existentes, na legislação social, entre empregador e empregado.

Surge a controvérsia: bastará, como no litígio Magalhães Júnior-Roulien, uma simples autorização, sem prazo e preço, para que, com exclusividade, possa o empresário encenar, em qualquer tempo, uma peça teatral ?

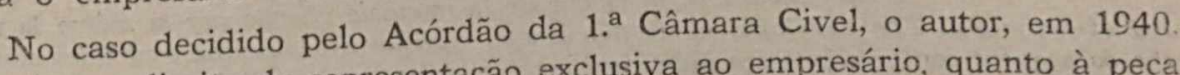
concedera o direito de representação exclusiva ao empresário, quanto à peça "O Imperador Galante". Decorridos doze anos, sem qualquer iniciativa do empresário, outorga o mesmo direito à Companhia Dulcina que resolve montá-la.

Ora, na primeira autorização, nada se convencionara, entre as partes, sôbre a forma de pagamento dos direitos autorais. Entretanto, o decreto número 5. 492, de 1928, na defesa da propriedade intelectual, para a representação dramática, exige a existência de contrato com tôdas as formalidades legais e como o reconhece a grande autoridade de Clovis Bevilaqua, onde se expressem os direitos dominicais do autor.

Citando HilsenRAD, em "Las Obligaciones Precontratuales" (pág. 21), conclui o relator Coelho Branco pela inexistência de contrato de representação, sem que êste se transforme em realidade juridica, pela forma disciplinada em lei, com obrigações e direitos recíprocos.

O outro aspecto da contenda gira em torno da autorização preliminar de 1940 constituir, ou não, um contrato de doação de autor ao empresário.

Como a doação, no direito brasileiro, não se presume, impõe-se, no ato, fique expressa a liberalidade de quem se empobrece em benefício do donatário. Acresce que o contrato de representação, por sua natureza, é oneroso. Novamente ressalta a lição de Clovis Bevilaqua: "a cessão de direitos do autor não se presume gratuita".

Recorrendo ao direito francês e italiano, verificaremos que, mesmo a ausência de preço estipulado no contrato de representação, não the retira o caráter oneroso, nem, no respectivo silêncio, ocorrerá alienação ou transferência da propriedade que é conservada pelo autor, tendo o empresário apenas o direito de um encontro de contas.

Com todo o acêrto, a decisão da $1 .^{\text {a }}$ Câmara Civil reputa inaceitável a tese da dcação, naquele contrato como inaceitável o entendimento preliminar, de 1940 , entre as partes, para valer como contrato, por the faltarem os requisitos essenciais.

Precisamos com energia, consolidar a defesa do direito do autor e, principalmente, do nosso autor virtualmente desamparado. Dispomos de uma lei com três anos, ainda não regulamentada, que obriga as nossas companhias teatrais a encenar certo número de originais brasileiros.

Estranhamente ainda não regulamentada aquela lei, possibilita, a olhos estrangeiros, a visão falsa de que não existem autores nacionais, porém simples tradutores de peças. Entretanto, surgem, dia a dia, autores desmentindo uma suposta incapacidade criadora. 
a justiça comutativa. Vivia-se naquele mundo de segurança, evocado por STEFAN ZWEIG, mundo de monarquias quase milenárias, de direitos fixos, de moedas estáveis.

A Côrte de Cassação francesa repudiava a cláusula implícita em julgamento publicado em janeiro de 1856. Já em 1900 todavia, a Côrte de Cassação de Turim aplica-a, despertando novo movimento doutrinário a respeito da matéria.

Mostra-nos o eminente civilista pátrio, Professor ARNOLdo MEDEIROS DA FonseCA, como, a partir de 1914, "a guerra veio dar nova atualidade ao assunto, pois, pelas suas conseqüências, criou um ambiente em que a imprevisão floresceu com um viço até então desconhecido, na expressão de VoIRIN. Surgiu assim, como Fenix, renascida das próprias cinzas, a modernamente chamada teoria da imprevisão pela qual, no caso de mudança das circunstâncias que constituiram o ambiente objetivo da formação do contrato, procura-se atender a impossibilidade subjetiva ou onerosidade excessiva da prestação dele decorrente". (3)

As legislações polonesa e italiana e o nosso ante-projeto de Código das Obrigações, respectivamente nos artigos $269,1.467-1.469$ e 322, assim como o novo Código Egípcio (artigo 147) e as jurisprudências alemã e suíça manifestaram-se favoráveis à revisão dos contratos. A teoria inglesa da frustration of adventure também ampliou a existência de uma implied condition (condição implícita) análoga à rebus sic stantibus e que data, no direito britânico da célebre decisão de 1647 no caso Paradine versus Jane em que um contrato foi rescindido por ter sido a casa objeto da locação ocupada por tropas inimigas. (4) A jurisprudência adminisrtativa francesa admitiu a teoria da imprevisão em diversos casos de concessões, sendo de conhecimento geral a decisão do Conselho de Estado de 1916 no processo da companhia de gás de Blordéus. (5) A jurisprudência da Côrte de Cassação, ao contrário, a rechaçou salvo os casos especiais da lei FAILliot.

No Brasil, a corrente favorável à teoria da imprevisão se sagrou vencedora depois da promulgação das leis que estabeleceram a renovaçãu judicial dos contratos de locação, o reajustamento econômico das dívidas dos agricultores e a revisão periódica das tarifas de serviços públicos explorados por concessão. (6)

2. Ao lado das cláusulas implícitas de revisão consolidadas pela teoria da imprevisão, os contratos passaram a incluir diversas cláusulas explícitas de revisão de acôrdo com certos índices escolhidos pelas partes. Convencionou-se pois uma modificação do contrato desde que variasse um dos elementos objetivos em função do qual fôra firmado. O fator escolhido foi inicialmente o ouro, a prata e outros metais preciosos. Depois, surgirarn as cláusulas valor ouro, pagamento em divisas estrangeiras ou em moeda na-

(3) Professor ARnoldo MEdeiros DA FonsecA, op. cit., loc. cit., p. 173.

(4) V. Arminjon, Nolde et WolfF, Traité de droit comparé, tome III, Paris, 1952, p. 144 e seguintes.

(5) ANDRÉ TRASBot, La dévaluation monétaire et les contrats de droit privé in Mélanges Ripert, Paris, 1950, tomo II, p. 159.

(6) Constituição federal, art. 151 \& único. 
cional de acôrdo com as variações do padrão estrangeiro. Outras mercadorias passaram a ser aceitas como índices: o valor do quintal de trigo ou do kilowatt de energia elétrica. Na Europa, diversos contratos aceitaram como índice para sua auto-revisão o custo da vida ou da construção em determinada região.

Tivemos assim contratos em que a prestação do devedor variava de acôrdo com uma escala móvel ou ciáusula escalar (escalator clautse ou clause d'échelle mobile), segundo as flutuações do índice geral de preços ou do preço de uma mercadoria determinada prèviamente convencionada.

A introdução da cláusula móvel implica pois numa revisão do contrato, revisão pre-convencionada e dependente das variações do índice escolhido.

3. As leis que nos diversos países estabeleceram o curso forçado da moeda (Alemanha, Austria, Bélgica, Brasil, Bulgária, Colômbia, Cuba, Costa Rica, Grécia, Inglaterra, Luxemburgo, México, Suécia, Rumânia, Iugo-eslávia, Franca e outros) (7) impediram a estipulação pelas partes do pagamento em ouro por ser contrária à ordem pública, dada a natureza imperativa da lei.

Posteriormente, a jurisprudência e a doutrina distinguiram entre a função jurídica e econômica da moeda. O Professor AsCARELli, no seu sempre atual ensaio sôbre a moeda, mostrou que juridicamente ela era um meio de pagamento em determinado país e em certo tempo, enquanto econômicamente significava um valor. Esta concepção fecunda, que está entrosada conı a distinção que o eminente comercialista italiano assinalou entre dívidas de dinheiro e de valor, permitiu que a jurisprudência reconhecesse a validez das cláusulas estabilizadoras que, embora conservassem a moeda como único meio legal de pagamento, obedecendo pois as normas estabelecidas em matéria de curso forçado, recorreu a um índice para fixar o quantum, o número de unidades monetárias que devem ser entregues ao credor para perfazer um valor pre-convencionado. O índice escolhido poderá ser - valor do ouro, de uma divisa estrangeira, do custo da vida ou da construção ou de determinada mercadoria ou ainda o próprio salário mínimo.

4. O direito comparado nos revela as oscilações da jurisprudência dos diversos países.

$\mathrm{Na}$ Bélgica, só foram consideradas ineficazes as cláusulas que previam o pagamento em ouro ou prata, (8) admitindo-se amplamente as cláusulas de escala móvel e até as de valor-ouro ou valor divisa estrangeira. (9)

A jurisprudência belga, interpretando o artigo 1.895 do Código Civil (10) e a lei que deu curso forçado ao franco papel, reconheceu a validez das cláusulas de pagamento de acôrdo com o valor do ouro ou das divisas

(7) V. JACqueline Reiss, Portée internationale des lois interdisant la clause or,

(8) Cassação belga 12-VI-1950 in Pasinomie, 1930, I, 245 e 27-IV-1933 in Belgique Judiciaire, 1933, col. 393.

(9) Decisões da Cassação belga de 30-V-1929 in Pasinomio, 1929-IV, 206, e de 12 de maio de 1932, Pas., 1932,I.167.

" seguinte o texto do artigo 1895: "L'obligation qui résulte d'un prêt en argent n'est toujours que la somme numérique énoncée au contrat. S'il y a eu augmen- 
estrangeiras, explicando o Conselheiro PIRET, professor na Universidade de Louvain, que "as restrições feitas ao pagamento em ouro ou em moeda estrangeira não se aplicam aos pagamentos que terão que ser feitos em francos papel para um quantum determinado de acôrdo com as modificações sofridas pelo franco ouro ou de acôrdo com as relações existentes entre o franco papel e o ouro ou entre aquele e determinada divisa estrangeira". (11)

$\mathrm{O}$ direito belga admite pois as cláusulas valor-ouro e valor divisa estrangeira e tanto mais a escala móvel condicionada a um índice variável qualquer, como o dos preços, dos salários ou de determinada mercadoria.

As duas primeiras cláusulas são todavia, por lei especial (decisão do Príncipe Regente de 15-II-1946), excluídas do domínio dos seguros.

Por outro lado, a legislação belga fixa os vencimentos dos funcionários e magistrados, assim como as pensões, de acôrdo com as flutuações do custo da vida.

5. Na França, a jurisprudência tem reagido de modo diverso diante das cláusulas estabilizadoras da moeda, mostrando mais uma vez que a analcgia dos textos legais nem sempre significa a identidade dos direitos realmente aplicados. (12)

Deu-se, na França, uma interpretação do artigo 1.895 muito diferente daquela firmada na Bélgica. Além disso, exigiu-se que as cláusulas operassem tanto em favor do credor como do devedor, inquinando-se de nulidade algumas delas por se presumir que, diante da desvalorização progressiva da moeda, só pudessem favorecer a uma das partes contratantes - o credor.

Assim foram banidas não sòmente as cláusulas de pagamento em ouro ou em moeda estrangeira mas também as cláusulas de pagamento em moeda legal de curso forçado de acôrdo com o valor do ouro ou das divisas, negando-se pois a importante diferenciação já assinalada e desenvolvida por ASCARELLI entre a função jurídica e econômica da moeda. (13)

Quanto à escala móvel, a jurisprudência francesa tem vacilado. Uma decisão da Côrte de Apelação de Paris de 22 de junho de 1953 admitiu a revisão de um contrato de arrendamento de uma fazenda de acôrdo com as variações do preço do quintal de trigo por não infringir as normas sôbre o curso forçado nem o disposto no artigo 1.895 , que considera de ordem pública, e por estabelecer um princípio de reciprocidade, já que a desvalorização da moeda não é o único elemento a condicionar as flutuações do preço do trigo, poder do a cláusula beneficar tanto o devedor como o credor.

tation ou diminuition d'espèces avant l'époque du payement, le débiteur doit rendre la somme numérique prêtée et ne doit rendre que cette somme dans les espéces ayant cours ayant au moment du payement.".

(11) R. PIRET, Les clauses de garantie centre les fluctuations de la monnaie et des prix en droit privé belge, in Revue de Droit International et de Droit Comparé, número especial compreendendo a contribuição belga ao $4 .^{\circ}$ Congresso da Academia Internacional de Direito Comparado, p. 78 e seguintes.

(12) MARC ANCEL, La tendance universaliste dans la doctrine comparatiste française du début du XXeme siècle in Festschrift furr Ernst Habel, 1st band, p. 31.

(13) V. Civ. 17-V-1927, in Dallez Périodique 1928, I, 25, conclusões do Procurador Matter e nota de Capitant e Requetes, 25-VI-1934, Dallon Hebdomadaire, 1934, 426. 
Já em 3 de novembro do mesmo ano a Côrte de Cassação anulou uma cláusula estabilizadora que tomara como índice o preço anual médio do custo de vida e que fôra incluída num contrato de mútuo. Esta decisão, embora considerasse que o artigo 1.895 já citado não é de ordem pública, recusou-se a tomar conhecimento da cláusula estabilizadora por the parecer contrária à lei do curso forçado já que o preço médio anual da vida-índice sufragado pelas partes - é exclusivamente condicionado pela desvalorização da moeda, não havendo outros elementos que possam influir na matéria.

Vemos pois grosiso modo que os tribunais franceses só reconhecem as cláusulas de escala móvel quando haja reciprocidade - podendo beneficiar tanto o devedor como o credor - e desde que entrou em jôgo outros elementos além da depreciação da moeda. Exige-se a presença de uma alea. Do mesmo modo que se proíbe a condição potestativa pura, condena-se a cláusula que subordina a variação das prestações tão sòmente à desvalorização da moedia.

Mostra o Professor Miguel Fenech, catedrático da Universidade de Barcelona, em interessante artigo intitulado - "Las cláusulas estabilizadoras en la jurisprudencia española e francesa" (14) - o desacêrto das distinções e das reservas da jurisprudência francesa em relação à escala móvel. A exigência de reciprocidade e o argumento de que a cláusula deve fazer referência a um índice não condicionado exclusivamente pelas flutuações da moeda não se justificam por ser exatamente a finalidade da escala móvel o estabelecimento de uma segurança contratual, de uma equivalência das presta. çôes independentemente da diminuição do valor real da moeda.

6. A jurisprudência espanhola ao contrário tem admitido amplamente e sem restrições as cláusulas estabilizadoras, a escala móvel e mesmo as cláusulas valor ouro ou valor divisa, aproximando-se mais da interpretação dada às leis pelos tribunais belgas.

A idéia de reciprocidade não foi acolhida na Espanha pois os riscos no caso só correm por conta do credor e não há imoralidade em assegurarem-se as partes contra tais riscos. O Tribunal Supremo Espanhol reconheceu a validez das cláusulas valor-ouro numa série de decisões em que julgou improcedentes as consignações feitas em papel moeda da época republicada quando os contratos consignavam que o pagamento seria em ouro ou de acôrdo com o valor de ouro. Exigiu a alta côrte espanhola, nas hipóteses citadas, que o pagamento fôsse feito na forma convencionada, não vendo na estipulação nenhuma infração à ordem pública espanhola. (15) Os tribunais, ao reconhecerem as mencionadas cláusulas, invocaram os princípios da justiça comutativa e a necessidade da eqüivalência das prestações.

Vemos que o velho "res perit domino" individualista está desaparecendo. Quando os autores, liderados por SAVATIER e RYPERT, começam a falar na "socialização dos riscos", o Estado reconhece o seu dever de atender à justiça distributiva, homologando as cláusulas estabelecidas pelas partes para que o

(14) In Revista del Instituto de Derecho Comparado, de Barcelona, n. ${ }^{\circ}$ 2, janeirojurho, 1954, p. 141-177.

(15) Decisões citadas no artigo citado na nota 14. 
contrato não se torne excessivamente oneroso para uma delas, lesando assim o interêsse social.

7. O Brasil, herdeiro das civilizações latinas, dos orçamentos deficitários e da política inflacionista que dominaram a velha Europa, não podia ficar alheio por muito tempo aos problemas surgidos com a depreciação monetária.

O Decreto-lei 23.501 de 27 de novembro de 1933 estabelecera que "qualq:zer estipulação de pagamento em ouro ou em determinada espécie de moeda, ou por qualquer meio tendente a recusar ou restringir, nos seus efeitos, o curso forçado do mil réis papel é considerada nula", sendo a matéria muito discutida em relação aos pagamentos em moeda estrangeira convencionados nos casos de empréstimos obtidos no exterior, cujas prestações deviam ser pagas na Inglaterra embora fôsse garantido o mútuo por hipoteca sôbre bens existentes no Brasil. Tal foi o caso, entre outros, da ação declaratória movida no fôro do Distrito Federal pela Companhia América Fabril S. A. contra The City Bank Farmers Trust Comp. Ltd., em que a companhia brasileira queria fazer os pagamentos em nossa moeda, por ser exequível a dívida no Brasil enquanto o banco iriglês procurou distinguir a exigibilidade da exequibilidade para receber o pagamento em libras esterlinas. Um movimento doutrinário se desenvolveu em tôrno do caso com a publicação dos pareceres dos Professores HaRoldo Valladão, Arnoldo Medeiros da Fonseca, Francisco Campos, Castro ReBEIo e NEHEMIAS GUEIROS.

problema se circunscreveu ao estudo da possibilidade de introdução nos contratos de cláusulas ouro ou valor-ouro, divisas estrangeiras ou valor-divisas. Não fêz o nosso juiz a distinção de ASCARELLI entre curso forçado - função jurídica da moeda - e determinação do quantum da moeda nominalista que deverá ser paga - função econômica. Não o pôde fazer o julgador brasileiro diante dos têrmos excessivamente candentes dos consideranda que precederam o decreto 23.501: "Considerando portanto, - diz o legislador - que não pode ter validade legal, no território brasileiro, qualquer cláusula, convenção ou artifício que vise subtrair o credor ao regime do papel moeda de curso forcudo, recusando-lhe ou diminuindo-1he o poder liberatório integral que o Estado, em sua soberania, the conferiu; Considerando que o contrário seria admitir a possibilidade de convenções de direito privado derrogarem leis de Direito Público....".

Manteve o nosso legislador os injustos preconceitos da doutrina francesa, clvidando o papel sobremaneira fecundo das cláusulas estabilizadoras.

A depreciação monetária crescente torna impossível os contratos a longo prazc, sendo pois causa de insegurança jurídica já que nãa há certeza do valor das prestações futuras. As cláusulas escalares ou estabilizadoras permitem conciliar a segurança jurídica, independentemente das flutuações da moeda e a justiça distributiva a que o direito contemporâneo veio dar tôda a sua inportância. Em matéria de contratos, de pensões, de rendas derivadas de casos de responsabilidade civil, de indenização pagas gradativamente durante longo prazo, de alimentos, de seguros, a revisão se impõe com a alta dos preços e seria de muito facilitada pela inclusão das cláusulas de escala móvel.

No Brasil, a lei não se referiu à escala móvel. A doutrina, fertil no domínio da revisão, não the dedicou a sua atenção a não ser incidentemente. A 
jurisprudência não teve oportunidade de apreciar a sua validez. Todavia a prática já a consagrou em certos contratos como, por exemplo, no domínio da empreitada de construção em que o preço ficou ligado a certo índice como o salário mínimo. (16)

Por outro lado, a lei estabelece o nível das pensões e aposentadorias e os próprios salários mínimos de acôrdo com o custo da vida em determinada região.

A introdução da cláusula escalar no domínio dos seguros nos parece de grande interêsse para a economia nacional, podendo estimular uma segurança individual que nos dias de hoje a depreciação contínua da moeda e a inflação crescente não mais permitem. Já, em França, permitiu-se a revalorização dos seguros de acôrdo com o índice estabelecido na base do custo da vida. (17)

Já alguns dos nossos juízes, nas condenações para o ressarcimento de atos ilícitos mandam que a indenização seja calculada de acôrdo com a proporção existente entre o salário da vítima e o salário mínimo vigente na época do acidente, adaptada tal proporção ao salário-mínimo em vigor no momento da condenacão. Interessante e justo seria que, nestes casos, a adaptação não fôsse feita tão sòmente para o presente mas também em relação ao futuro, condicionando-se a renda, recebida pela vítima ou por aqueles que dele econômicamente dependiam, às flutuações do salário estabelecido por lei. Tal modificação criaria um problema de ordem processual de fácil solução já que atualmente a renda é oriunda dos juros de títulos da dívida pública federal (artigos 911 e 912 do Código de Processo Civil).

Na realidade, como o notou o Professor FENECH, a cláusula estabiliza. dora é um freio à inflação pois o maior perigo do papel moeda é a tentação que seduz os governos de criarem uma riqueza aparente mediante a multiplicação de uma moeda que nada lhes custa. (18)

Em recente artigo publicado na Revue Trimestrielle de Droit Civil, (19) - Professor MAZEAud assinalou que a inflação de verdade "tout court" que era, devia passar a ser considerada também como verdade jurídica. Verdade que os juristas não podem olvidar. Ignorar o problema não é resolvê-lo. O jurista constroi sistemas, colaborando na criação de um meio em que se concilien os supremos ideais do direito - a justiça e a segurança - procurando forjar os instrumentos necessários para que saiamos da profunda crise em que nos encontramos.

Talvez a cláusula escalar seja um dêsses instrumentos.

\section{SUMMARY}

The escalator clause as a corollary of the theory of unpredictability. The principle The escalator clatuse as a corollary of the doctrine, which devoloped up to the 15th
rebus sic tantibus. Mediaeval foundations of the century to prevail until the beginnings of the 19 th century.

(16) Alfredo de Almeida Paiva, A cláusula rebus sic stantibus na empreitada de construção in Revista Forense, vol. 141, 1952, p. 29-34.

(17) ANDRÉ BESSON, Los seguros con cláusula indice y revalorizables in Cuadernos de Derecho Frances, Barcelona, n. ${ }^{\circ}$ 2, janeiro-junho, 1954, p. 35-44.

(18) Artigo citado, p. 173.

(19) Revue Trimestrielle de Droit Civil, 1951, p. 507. 
The Napoleon Code and the principle pacta sunt servandi. Influence of the doctrine of naturat law. The fixity of rights, the stability of currency.

The First World War and the modern theory of unpredictability as a reflex of unstable social conditions. The Polish, Italian and Egyptian legislation. The German and Swiss jurispruderice. The proposed Code of Obligations in Brazil, and the recent laws on (1) judicial modification of contracts of rent, (2) economic readjustment of debts of farmers and (3) juridical tariff revision of concessionaries of public utility services.

The explicit clause of revision according to some okjective index formally declared. The gold clause prohibited in countries where prevails the system of non-convertible paper currency. The distinction between the juridical and economical functions of currency, and the validity of the gold clause as a stabilizing one.

Vacillation of jurisprudence in several countries as regards the escalator clause. The Brazilian law of 1933 does not recognize validity to such clause.

The necessity of conciliation between juridical security an distributive justice requiring acceptance of the escalator clause, especially in fields such as insurance, civil contracts, retirement allowances and pensions, income derived from civil responsibility and indemnities paid by installments.

The escalator clause accepted in practice, in Brazil, although not expressly regulated. by law, in matters such as Euilding (prices liable to fluctuate according to changes of minimum wages), retirement allowances, fixing of minimum wages.

The escalator clause as an anti-inflationary measure. Inflation as a fact to be recognized as a juridical truth.

Aproximar os povos pelo espírito e pela inteligência tem sido no Brasil uma política tradicional de ação prática que sempre correu paralela aos ideais de harmonia e concórdia. Desde o século passado que a diplomacia brasileira se projeta alem fronteiras na defesa dos postulados da justiça internacional e nas campanhas em prol das soluções amistosas. (Germano Jardim, In "A Administração Pública e a Estatística", Imprensa Nacional, 1940, Rio de Janeiro). 